\title{
Blended wing body with Boundary layer Ingestion conceptual design in a multidisciplinary design analysis optimization environment
}

\author{
Ziang Gao, ${ }^{1}$ and Howard Smith. ${ }^{2}$ \\ Cranfield University, Bedford, MK43 OAL, UK
}

\begin{abstract}
This paper introduces the GENUS multidisciplinary concept level aircraft design and analysis environment developed by Cranfield University in recent years and it has been applied to the conceptual design of blended wing body (BWB) aircraft. Analytical disciplines include a variety of low-to-medium fidelity, physics-based and empirical methods, and aerodynamic analysis of high-order panel method. Boundary layer ingestion (BLI), as a special module, has been incorporated into the aerodynamic and propulsion analysis. The results of the Cranfield BW-11 are presented. In the highly-constrained design space, a type of highly fuel- efficient BWB concept can be studied, and the advantages of the BLI concept can also be explored based on this framework.
\end{abstract}

\section{Nomenclature}

$\begin{array}{ll}C_{F} & =\text { skin friction coefficient } \\ C_{D} & =\text { drag coefficient } \\ C_{L_{\alpha}} & =\text { lift coefficient curve slope } \\ C_{m_{\alpha}} & =\text { moment coefficient curve slope } \\ F F & =\text { form factor } \\ M_{c r i t} & =\text { local critical Mach number } \\ M_{d d} & =\text { drag divergence Mach number } \\ P_{K} & =\text { mechanical energy added to flow by propulsion } \\ S_{r e f} & =\text { reference area } \\ S_{w e t} & =\text { wet area } \\ X_{a c} & =\text { aerodynamic center on } \mathrm{x} \text { axis } \\ X_{C G} & =\text { center of gravity position on x axis } \\ \Phi & =\text { energy dissipation } \\ \theta & =\text { momentum thickness } \\ \delta^{*} & =\text { displacement thickness } \\ v_{E} & =\text { boundary layer edge velocity }\end{array}$

\section{Introduction}

The desire to produce an environmentally friendly aircraft that is aerodynamically efficient and capable of conveying large number of passengers over long ranges at reduced direct operating cost led aircraft designers to develop the Blended Wing Body (BWB) aircraft concept [1]. The BWB aircraft represents a paradigm shift in the design of aircraft. The design provides aerodynamics and environmental benefits and is suitable for the integration of advanced systems and concepts like laminar flow technology, jet flaps and distributed propulsion.

\footnotetext{
${ }^{1}$ Ph.D. student, School of Aerospace Transport and Manufacturing, AIAA Student Member.
}

${ }^{2}$ Professor, School of Aerospace Transport and Manufacturing, AIAA Senior Member. 
Boundary Layer Ingestion (BLI) is an important technology for the BWB, and is currently being researched as a potential method to improve efficiency and decrease emissions for next generation of commercial aircraft. While reenergizing the boundary layer formed over the fuselage of an aircraft has many system level benefits, ingesting the low velocity boundary layer flow through the inlet into a turbofan engine adversely affects the performance of the engine. The BWB with BLI is a revolutionary concept, which offers several advantages but also a lot of design challenges hence design tools are still at the rudimentary stage. There is the need to develop a comprehensive design tool that addresses inherent challenges early in the design process and permits effective exploration of the design space. This design tool should integrate a physics-based mass estimation and a reliable aerodynamic analysis model, rather than conventional aircraft focused empirical models, into a multivariate optimization framework.

To overcome this issue, a multidisciplinary design analysis and optimization (MDAO) environment was developed in Cranfield University's Aircraft Design Group [2]. The GENUS aircraft design environment has been applied to a hypersonic space design [3], a solar UAV design, and supersonic business jet design [4]. A turbofan airliner model [6] was used to validate the environment.

In the following section, an overview of the design philosophy and disciplinary models of the MDAO environment is introduced. The next section describes the detailed architecture of each module and the appropriate methods and results to model BWB concepts. The last section discusses the conclusions and future work.

\section{GENUS Aircraft Design Environment}

The MDAO aircraft design environment is called GENUS [2], which has been developed by Aircraft Design Group at Cranfield University since 2012. It is a comprehensive tool for computational design that allows reuse of the design process and integrates the different disciplinary models in a modular, scalable, flexible and independent arrangement. Its name derives from the taxonomical classification of biological organisms (as shown in Fig. 1), and it represents the ability to model and analyze different species of aircraft under a common framework.

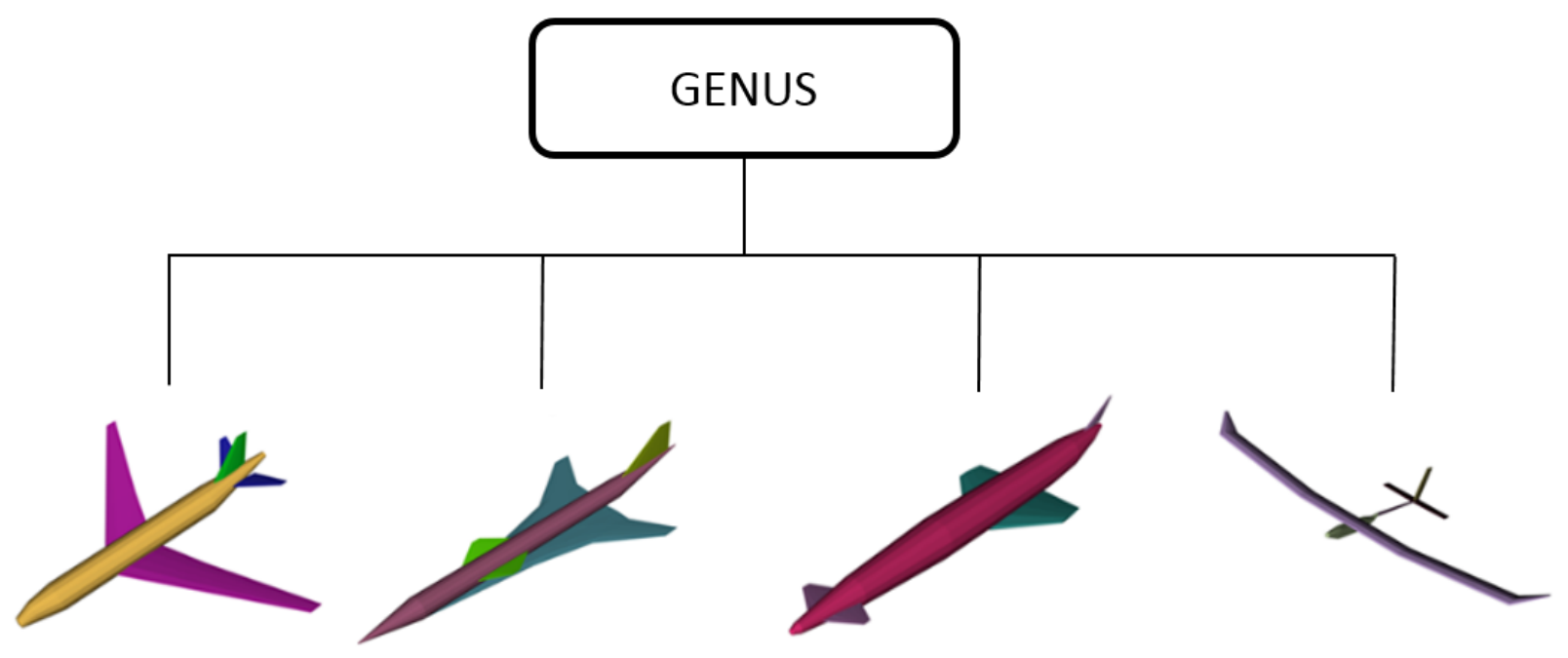

Fig. 1 GENUS geometry representation of various aircraft species

GENUS is a Java-based architecture, consisting of nine essential modules: 1) geometry, 2) mission, 3) propulsion specification, 4) mass breakdown, 5) aerodynamics, 6) propulsion, 7) packaging and C.G., 8) performance, and 9) stability. Special modules can be added to meet the needs of the specific aircraft designs. The modules are linked together tightly, which makes the multidiscipline design optimization possible. The structure of the design modules in GENUS showing data interactions between the 9 essential modules is shown in Fig.3. Furthermore, gradient-based and custom-made genetic algorithms also have been built in the framework for design space exploration. 


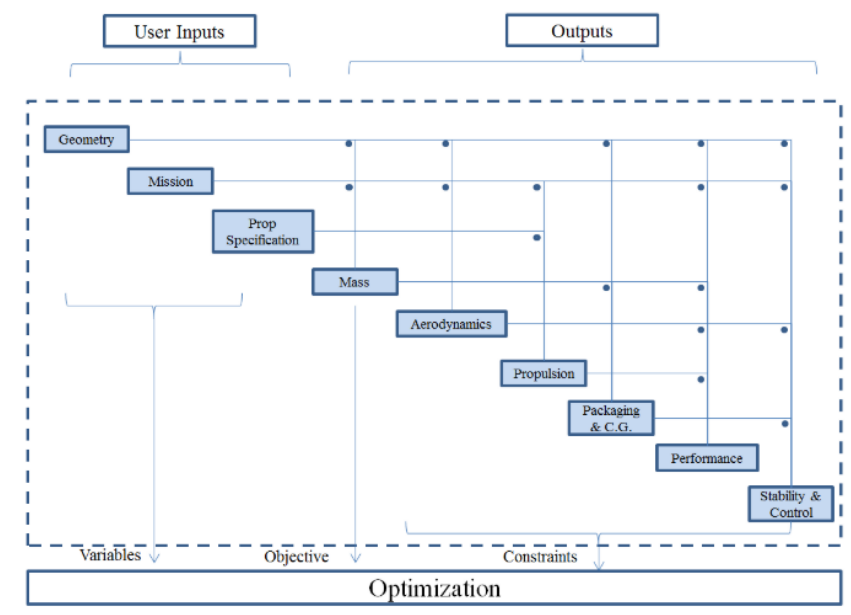

Fig. 2 Modules and data flow of GENUS

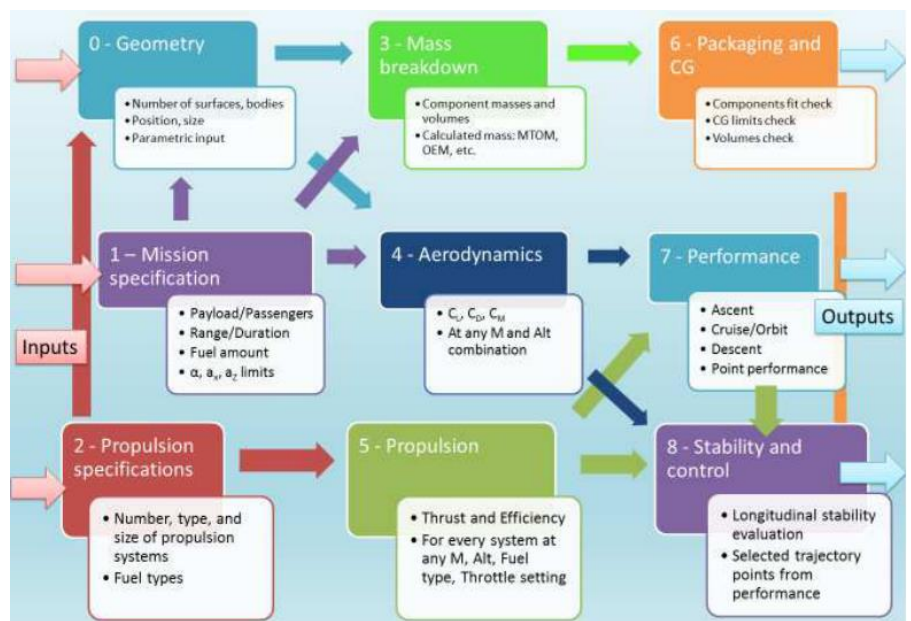

Fig. 3 Interaction between Modules in GENUS

\section{BWB Design and Analysis Methodologies}

An integrated process for multi-fidelity, multidisciplinary, design analysis and optimization for high fuel efficiency BWB concept has been completed. This integrated process includes mission, geometry, mass, propulsion specification, propulsion, packaging and center of gravity, aerodynamics, performance, stability, and optimization. Boundary layer ingestion is a special module to estimate the performance of the BWB concept with BLI.

\section{A. Geometry Generation}

The geometry parts are abstracted into lifting surface array and body component array, which provides great flexibility for designers [2]. The lifting surface array is then specified as wing, horizontal tail, vertical tail or canard. The body component array is then specified as fuselage, engine pod, external tank or tail boom. In addition, different geometry formats (such as XYZ point-clouds, and LAWGS) are used to link the geometry inputs to various analytical procedures, such as aerodynamics and packaging. Fig. 4 depicts the variables in the geometry module and Fig. 5 is the BWB geometry which is generated by the current geometry module. 


\begin{tabular}{|c|c|c|c|c|c|c|c|}
\hline Name & List & Value & Int Value & Optimize & Lower bound & Upper bound & \\
\hline Pre-set geometry & Custom & & & $\square$ & & & $\Delta$ \\
\hline Config.type & withTail & & & $\square$ & & & \\
\hline VTail.type & Winglet & & & 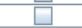 & & & \\
\hline Wing.kinks [-] & & & 3 & 吕 & & & \\
\hline Wing.span.0 $[\mathrm{m}]$ & & 28.635 & & 口 & 0 & 0 & \\
\hline Wing dihedral.0 [deg] & & 0 & & 吕 & 0 & 0 & \\
\hline Wing.sweep.0 [deg] & & 63 & & $\square$ & 0 & 0 & \\
\hline Wing controlsurfratio. $0[-]$ & & 0.75 & & $\square$ & 0 & 0 & \\
\hline Wing.span. $1[\mathrm{~m}]$ & & 5.735 & & 吕 & 0 & 0 & \\
\hline Wing.dihedral.1 [deg] & & 1.5 & & $\square$ & 0 & & 5 \\
\hline Wing.sweep.1 [deg] & & 38.3 & & $\square$ & 0 & 0 & \\
\hline Wing controlsurfratio. $1[\mathrm{H}]$ & & 0.75 & & 吕 & 0 & 0 & \\
\hline Wing.span. $2[\mathrm{~m}]$ & & 7.652 & & 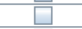 & 0 & 0 & \\
\hline Wing.dihedral. 2 [deg] & & 3 & & $\square$ & 0 & 0 & \\
\hline Wing.sweep. 2 [deg] & & 38.3 & & $\square$ & 0 & 0 & \\
\hline Wing controlsurfratio. $2[-]$ & & 0.75 & & $\square$ & 0 & 0 & \\
\hline Wing.span. $3[\mathrm{~m}]$ & & 19.449 & & $\square$ & 0 & 0 & \\
\hline Wing.dihedral. 3 [deg] & & 3 & & $\square$ & 0 & 0 & 5 \\
\hline Wing.sweep. 3 [deg] & & 38.3 & & 吕 & 0 & 0 & \\
\hline Wing.controlsurfratio. $3[-]$ & & 0.75 & & $\square$ & 0 & 0 & \\
\hline Wing.chord. $0[\mathrm{~m}]$ & & 48 & & $\square$ & 0 & 0 & \\
\hline Wing.airfoil.0 & NACA4 & & & 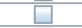 & & & \\
\hline Wing.airfoil.0.inp0 & & 0.04 & & $\square$ & 0 & 0 & \\
\hline Wing.airfoil.0.inp1 & & 0.4 & & $\square$ & 0 & 0 & \\
\hline Wing.airfoil.0.inp2 & & 0.17 & & $\square$ & 0 & 0 & \\
\hline Wing.twist.0 [deg] & & 2.8 & & 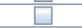 & 0 & 0 & \\
\hline Wing.chord. $1[\mathrm{~m}]$ & & 22 & & 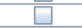 & 0 & 0 & \\
\hline Wing.airfoil.1 & NACA4 & & & 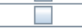 & a & & \\
\hline Wing.airfoil.1.inp0 & & 0.04 & & 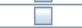 & 0 & 0 & \\
\hline Wing.airfoil.1.inp1 & & 0.4 & & $\square$ & 0 & 0 & \\
\hline Wing.airfoil.1.inp2 & & 0.12 & & $\square$ & 0 & 0 & \\
\hline Wing.twist.1 [deg] & & -0.3 & & $\square$ & 0 & 0 & \\
\hline Wing.chord. $2[\mathrm{~m}]$ & & \begin{tabular}{ll|}
14.69 \\
\end{tabular} & & $\square$ & 0 & 0 & \\
\hline Wing.airfoil.2 & NACA4 & & & $\square$ & a & & \\
\hline Winn aiffoil 2 inn & & 004 & & 늠 & 0 & & - \\
\hline
\end{tabular}

Fig. 4 Variables in the geometry module

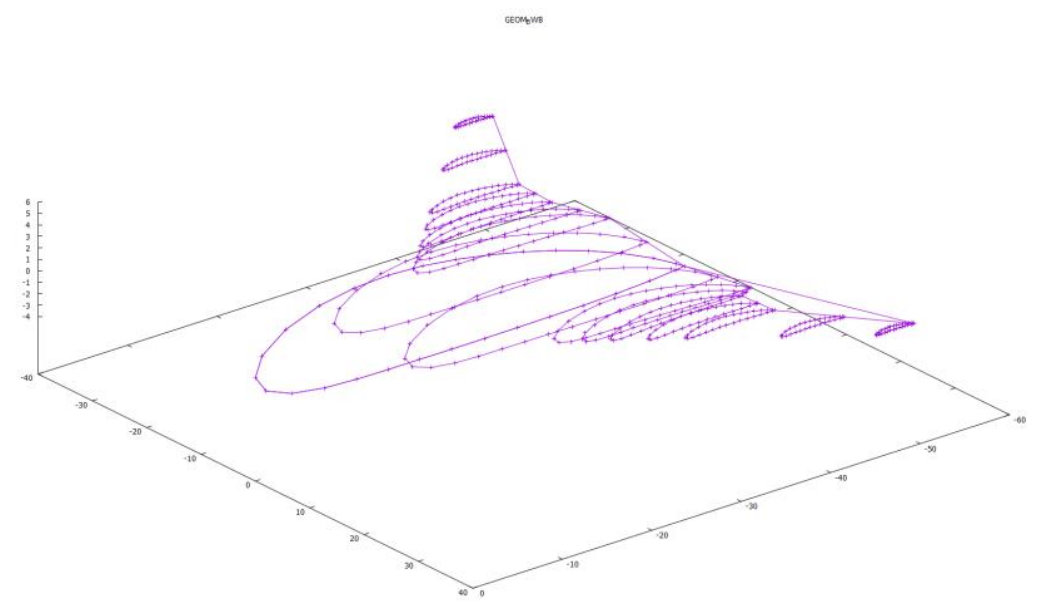

Fig. 5 View of BW11 generated in GENUS

\section{B. Mission Profile}

The mission module specifies several flight requirements for a design. These requirements are derived from the market or customer specification. It is defined by estimated take-off mass, target range, cruise Mach or speed, cruise altitude, loiter time and altitude, payload, droppable, and retrievable payload. These variables will be used for subsequent analytical procedures. A typical mission consists of the take-off, climb, cruise, descent and landing as shown in Figure 6. 


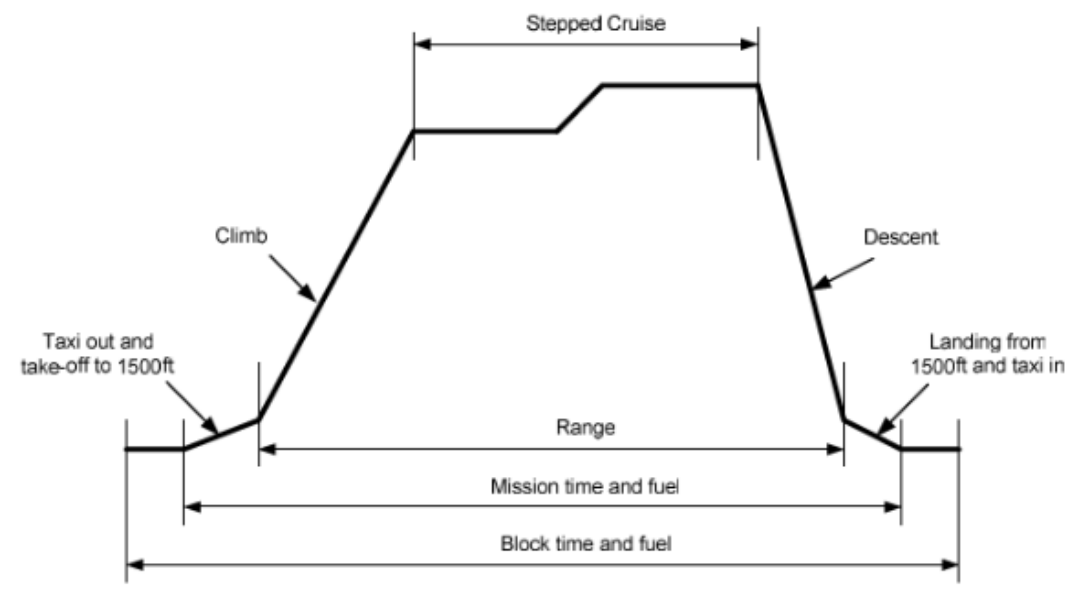

Fig. 6 Typical Main Mission Profile of a Commercial Transport Aircraft

\section{Propulsion Specification and analysis}

The propulsion specification module specifies the type of engine and fuel to use as well as design point and limits for the propulsion system. This information is used by the propulsion analysis module to obtain engine performance under a wide range of flight conditions

In the propulsion analysis module, some low-fidelity methods including semi-empirical regression equations have been built such as those proposed by Raymer [8] and Howe [9] for turbojet/turbofan engines. At a higher fidelity level, NASA's open source applet EngineSim [10] has been integrated in GENUS. This simple tool allows the user to set an engine design point, which can then be frozen to obtain the off-design engine performance.

\section{Mass breakdown}

The mass breakdown module calculates the mass of structural components, power plants, systems and equipment with mass prediction methods. The shape, dimension, and position of the mass items are predicted for center of gravity calculations and for packaging checking.

Mass prediction can be categorized into finite element, empirical and the semi-empirical approaches. The semi empirical method is the most suitable weight prediction method for conceptual design synthesis. This is because they are fast and easy to implement and accurate sufficiently for the conceptual design phase. The BWB mass breakdown module implements the Bradley semi - empirical [14] method, the Howe [15] empirically weighted theoretical BWB airframe mass estimation approach and Cranfield in-house mass estimation method to realize the weight prediction.

\section{E. Packaging}

Packaging is an essential module in the conceptual design synthesis of the BWB. It is necessary for the determination of the center of gravity of an aircraft which subsequently affects the stability and control of the configuration and to ensure that internal objects are well contained within the geometry. Ensuring items are completely contained within the geometry is critical in the design of the BWB due to the configuration's non-uniform crosssection. The packaging module consists of sizing, estimation of the center of gravity, geometry parameterization and volume constraint handling. The BWB passenger cabin is sized following the Bradley [14] sizing method. 


\section{F. Aerodynamic Analysis}

The linear potential solver Panair [16] has been integrated into the GENUS framework for aerodynamic analyses through a dynamic link library (DDL), which is shown in Fig. 7. Panair uses a higher order panel method; that is the singularity strengths are not constant on each panel, which allows Panair to analyze flow about arbitrary bodies for subsonic and supersonic flows, which is a distinct advantage over other panel methods. Panair provides surface flow properties (flow directions, pressures and Mach number), configuration forces and moments, sectional forces and moments, and pressures.

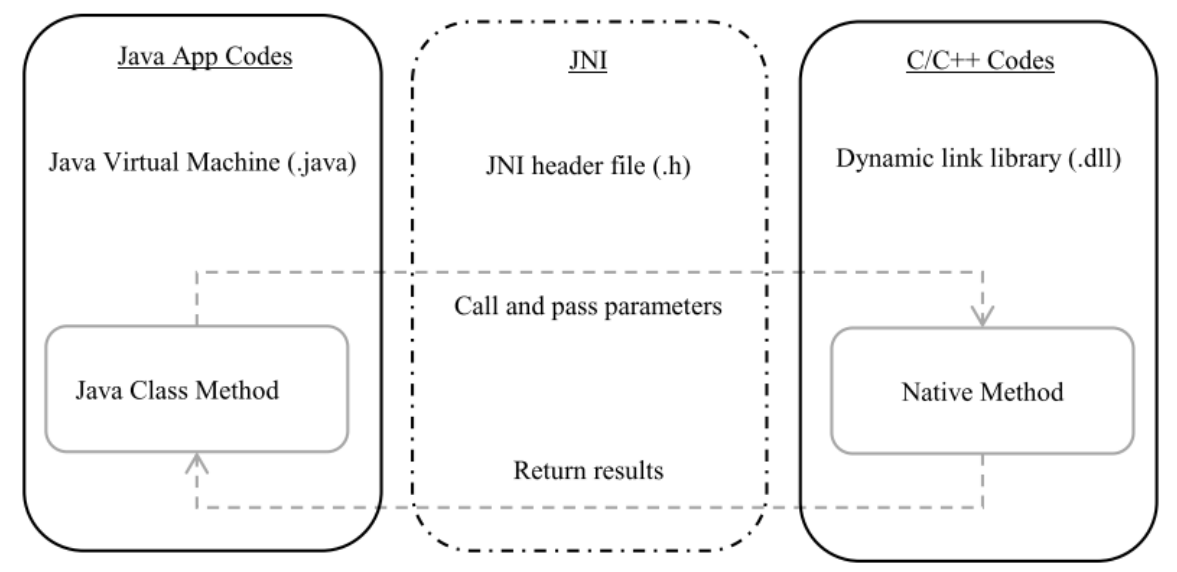

Fig. 7 Framework for integrating FORTRAN code into JAVA

As for the zero-lift drag, form factor method [15] has been chosen to calculate the skin friction and form drag. The total zero-lift drag comes from the summation of each component, as shown in Eq. (1).

$$
C_{D_{0}}=\sum_{j=1}^{N} \frac{F F_{j} C_{F_{j}} S_{\text {wet }}}{S_{r e f}}
$$

Where $\mathrm{N}$ is the number of components used to model the configuration.

The wave drag is estimated using Lock's fourth power rule which uses the critical Mach number computed by the following equations:

$$
\begin{gathered}
M_{c r i t}=M_{d d}-0.108 \\
C_{D_{w}}=20\left(M_{\infty}-M_{c r i t}\right)^{4}
\end{gathered}
$$

\section{G. Control and Stability}

The BWB has good aerodynamic potential but fairly complicated stability challenges caused by the short moment arm and poor trim characteristics [7]. This module assesses the longitudinal static stability of a BWB by determining the static margins and trim characteristics. The outputs of this module are usually calculated results and error indicators that state whether the aircraft is stable or not in a given flight condition, speed regime and/or the whole mission envelope, which can be used to drive the optimization process.

The static margin is defined as:

$$
K_{n}=\frac{X_{a c}-X_{c g}}{\bar{c}}=-\frac{C_{m_{\alpha}}}{C_{L_{\alpha}}}
$$


Due to the short moment arm and tailless nature, trim characteristics is particularly expedient for a BWB design. According to Castro [21], a BWB aircraft trim characteristics is assessed by its trim angle of attack as Eq. (5) and the elevon deflection angle for trim as Eq. (6).

$$
\begin{gathered}
\alpha_{\text {trim }}=\frac{C_{K} C_{L \delta e}-C_{B} C_{m \delta e}}{D e t} \\
\delta_{\text {etrim }}=\frac{C_{B} C_{m \alpha}-C_{L \alpha} C_{K}}{D e t}
\end{gathered}
$$

Where:

$$
\begin{aligned}
& \text { Det }=C_{L \delta e} C_{m \alpha}-C_{L \alpha} C_{m \delta e}, \\
& C_{K}=-C_{m 0}, \\
& C_{B}=C_{L t i r m}-C_{L 0}
\end{aligned}
$$

\section{H. Special module---Boundary layer ingestion}

The increased demand for air transportation and the growing emphasis on environmental sustainability have led to enhanced interest in fuel efficiency. Boundary layer ingestion (BLI) has the potential to provide step improvements in fuel consumption and has been proposed for a number of advanced subsonic transport aircraft concepts, including hybrid and blended wing bodies. This module aims to get a better understanding of BLI and to estimate its benefits.

BLI concept has highly coupled and complex interactions in terms of aero-structures, aerodynamics and propulsion-airframe integration, which leads to ambiguous definitions of thrust and drag. Thus, the Power balance method [11] (Eq.7) has been chosen to derive parametric expressions for the aircraft's net streamwise force (drag minus thrust for a conventional aircraft) and for the associated propulsive power as functions of the airframe and propulsion parameters. The energy dissipation for an airframe with BLI is shown in Fig. 8.

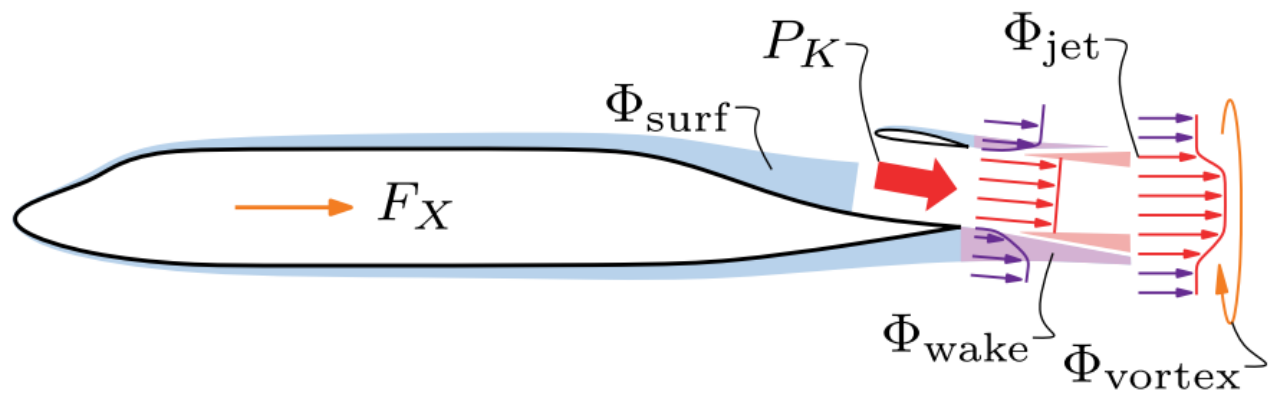

Fig. 8 Energy dissipation for an airframe with BLI [12]

$$
P_{K}-\Phi_{\text {jet }}=\Phi_{\text {surf }}+\Phi_{\text {wake }}+\Phi_{\text {vortex }}-F_{X} V_{\infty}
$$

The required boundary layer data including the displacement thickness $\delta^{*}$ and momentum thickness $\theta$ are generated with XFOIL for 2D subsonic airfoils. Since the XFOIL data does not provide the velocity distribution of the boundary layer, it is necessary to build an alternative model with a region of constant velocity $v_{B L}$ and finite thickness $\delta_{B L}$ in order to create an easily manageable initial situation for further calculations, which is shown in Fig.9. Following Budziszewski, N., \& Friedrichs, J.'s procedure [17], these parameters can be calculated by the displacement thickness $\delta^{*}$ and momentum thickness $\theta$. Generally, the momentum thickness is defined by:

$$
\theta \cdot v_{E}^{2}=\int_{0}^{\delta} v(y) \cdot\left(v_{E}-v(y)\right) d y
$$

where the variable $v_{E}$ is the boundary layer edge velocity. Applying the integral to the described substitution model results in:

$$
\theta \cdot v_{E}^{2}=\int_{0}^{\delta_{B L}} v_{B L} \cdot\left(v_{E}-v_{B L}\right) d y=\delta_{B L} \cdot v_{B L} \cdot\left(v_{E}-v_{B L}\right)
$$

The displacement thickness is defined as follows: 


$$
\delta^{*} \cdot v_{E}=\int_{0}^{\delta}\left(v_{E}-v(y)\right) d y
$$

A similar integral manner is applied into the substitution model:

$$
\delta^{*} \cdot v_{E}=\int_{0}^{\delta_{B L}}\left(v_{E}-v_{B L}\right) d y=\delta_{B L} \cdot\left(v_{E}-v_{B L}\right)
$$

Following expression for and the thickness $\delta_{B L}$ and the velocity $v_{B L}$ can be derived from Equations (9) and (11):

$$
\begin{gathered}
\delta_{B L}=\frac{\delta^{*}}{\left(1-\frac{v_{B L}}{v_{E}}\right)} \\
v_{B L}=\frac{\theta}{\delta^{*}} \cdot v_{E}
\end{gathered}
$$

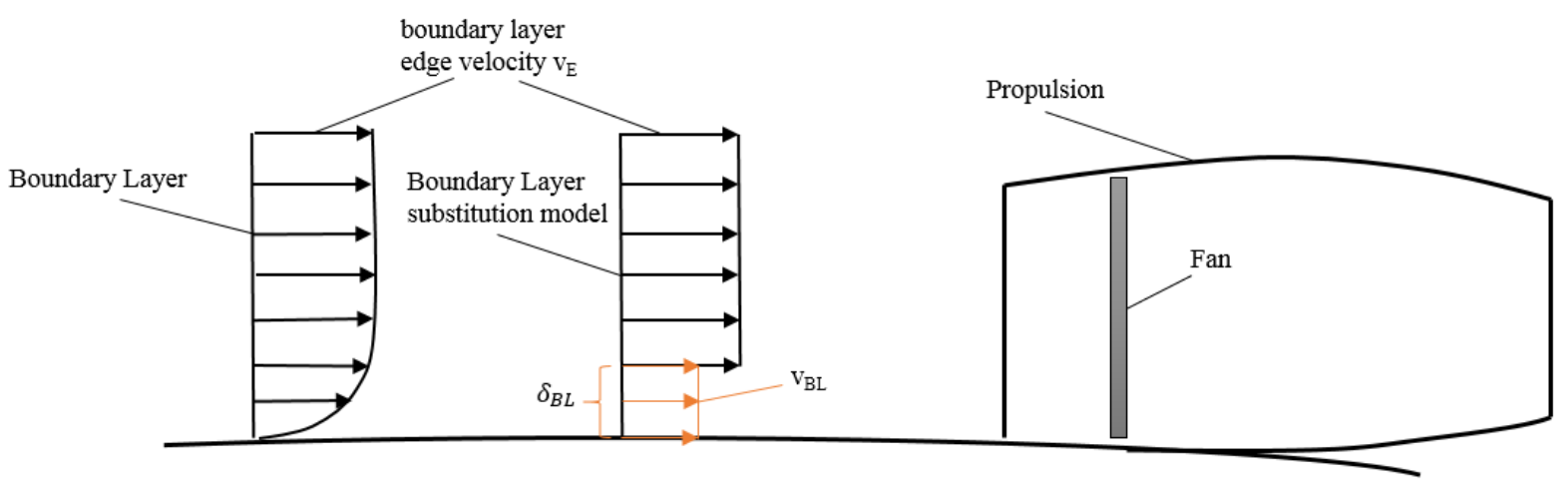

Fig. 9 Boundary layer substitution model

A parallel compressor model approach is used to analyze the impact of the ingested low velocity fluid which leads to a non-uniform inflow. The basic idea of a parallel compressor model is to substitute a compressor which encounters inflow distortion with two identical hypothetical compressors working at different operating points. The operating characteristic of the two sub-compressors matches the undistorted original characteristic. After getting the two operating points in the distorted and undistorted conditions, the area-weighted mean value has to be calculated to deduce a single operating point.

The process structure of this module is illustrated in Fig. 10.

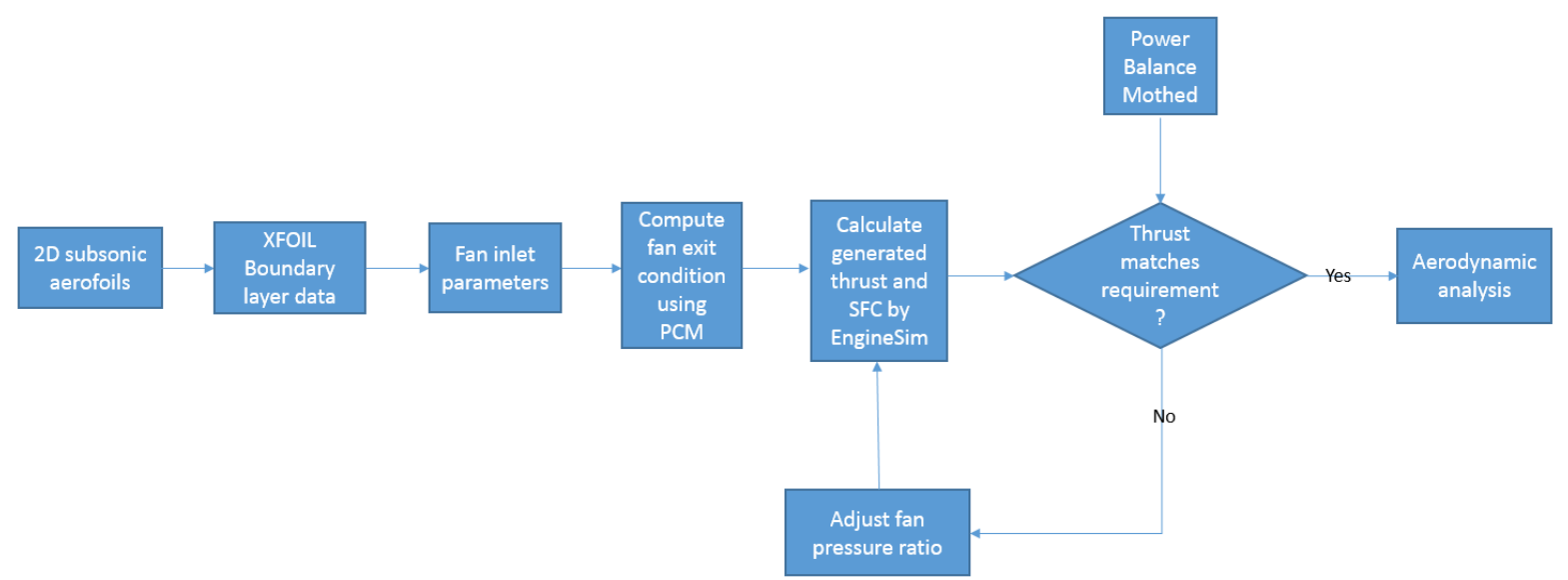

Fig. 10 Process structure of BLI calculation 


\section{Application to the Cranfield BW-11 Aircraft}

The Cranfield BW-11 Aircraft was designed by staff and post graduate students at Cranfield University. It is similar in size and range to conventional aircraft such as the A380. It is designed to explore the challenges and benefits BLI application on BWB concept. The general configuration of the BW-11 is shown in Fig. 11.
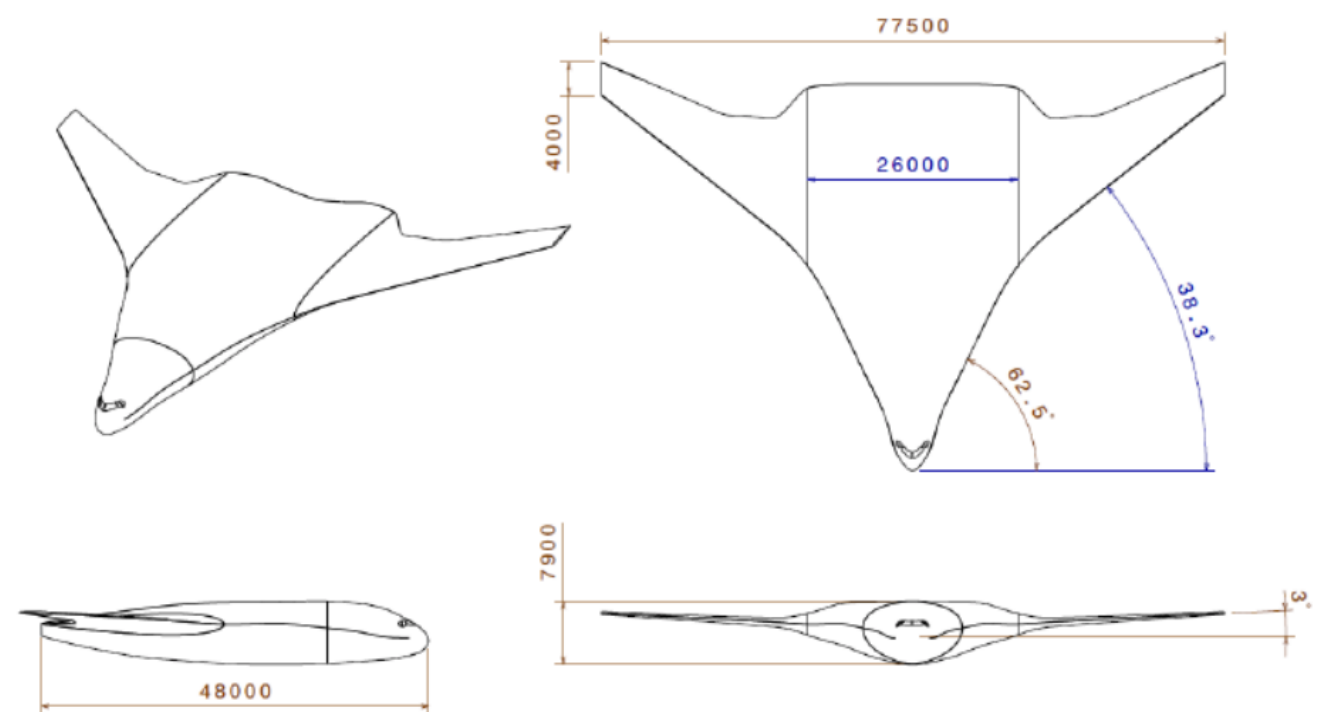

Fig. 11 Dimensions of the Cranfield BW-11 Blended Wing Body configuration (units in mm)

Assuming the advances in technology, it is assumed to be in service by c. 2030. The initial specifications accommodated during the conceptual design phase of $\mathrm{BW}-11$ are presented in the table 1 below:

Table 1 Initial specification

\begin{tabular}{c|c}
\hline Type & Definition \\
\hline Passengers & 555 \\
\hline Range(nm) & 7650 \\
\hline Span(m) & 77.5 \\
\hline Wing Aspect Ratio & 7.14 \\
\hline Cruise Mach & 0.85 \\
\hline Cruise Altitude $(\mathrm{m})$ & 10059 \\
\hline Estimated MTOW $(\mathrm{kg})$ & 456483.6 \\
\hline
\end{tabular}

The mass breakdown of the BW-11 is shown in Fig. 12. The fuel accounts up to $41.13 \%$ of the calculated total mass. The operational empty mass is about $60 \%$ of the calculated total mass. 


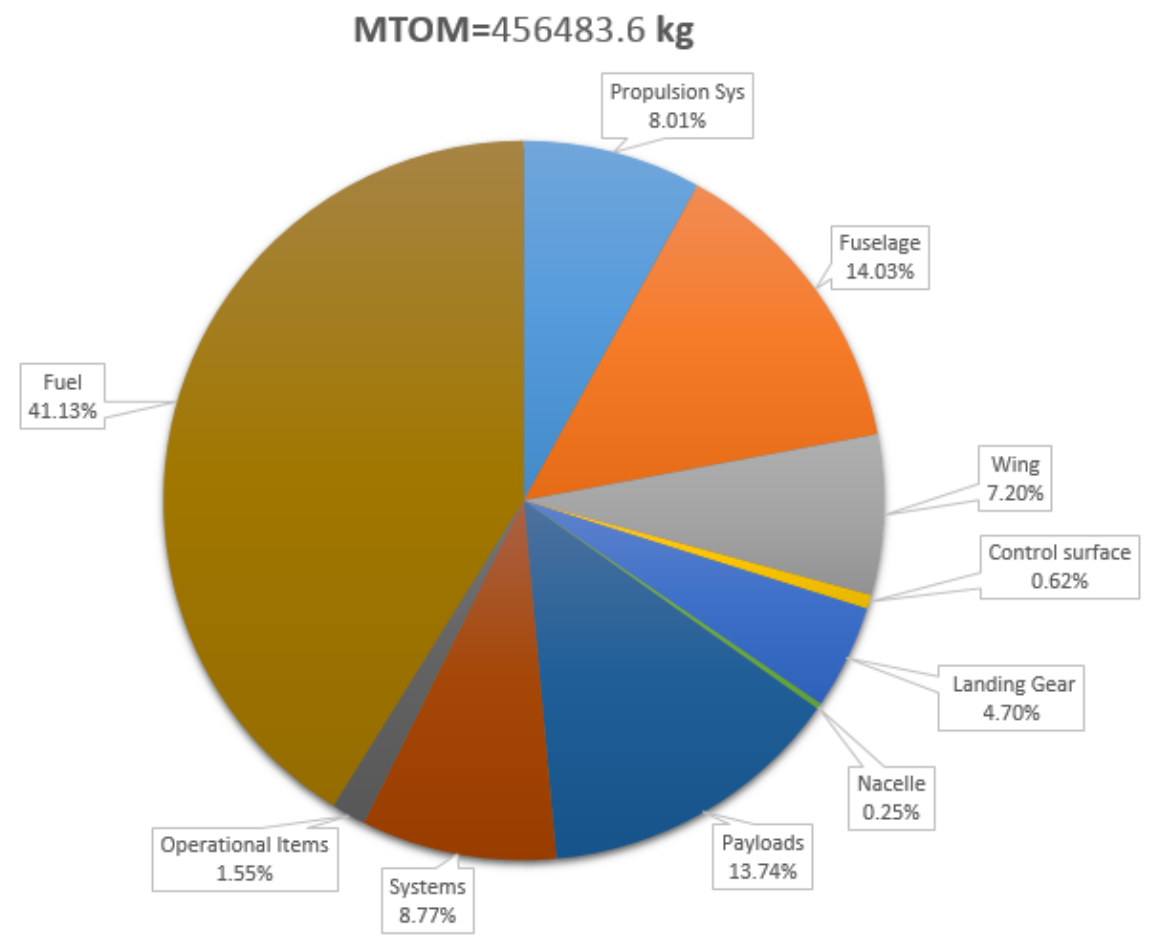

Fig. 12 Mass breakdown of BW-11

As for the aerodynamic performance, the BW-11 was analyzed for a range of Mach numbers within the operating envelope of the aircraft at angles of attack between -5 and $20^{\circ}$. The relationships between the lift and drag with angles of attack at low and high subsonic Mach numbers are shown in Fig. 13.
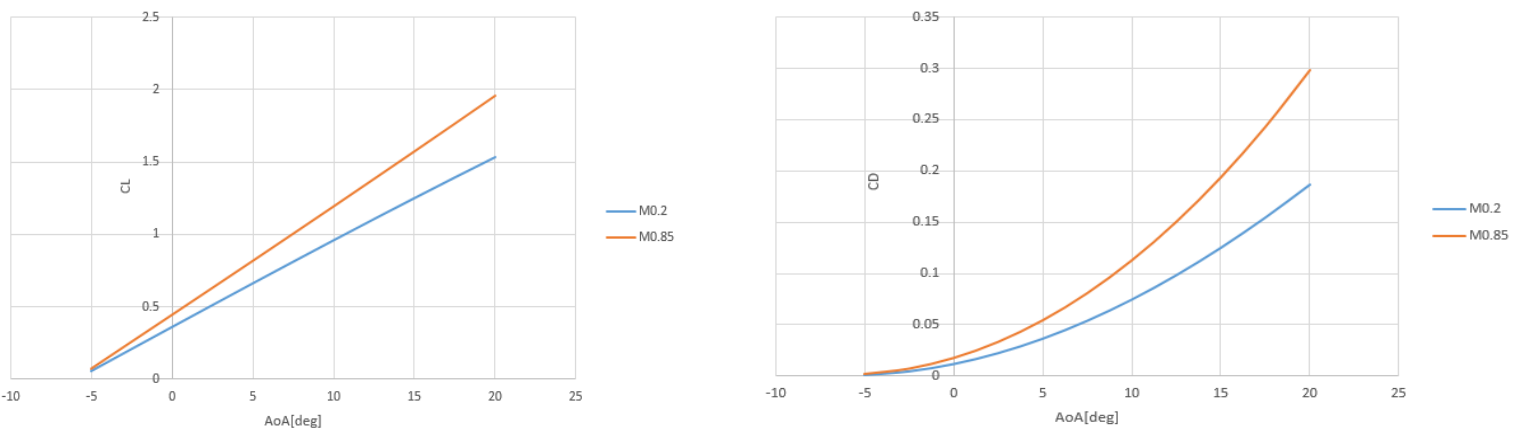

Fig.13 Graphical Relationship Between Aerodynamic Forces at Low and High Subsonic Mach Numbers

As for the boundary layer ingestion module, the development of the boundary layer displacement and momentum thickness along the upper side of the profile is depicted in Fig. 14. The NASA axial flow fan stage 53 [18] operating at 1.35 pressure ratio and the core engine of CFM567B26 are selected as the test case. Table 2 summarizes the main engine specifications and fan design characteristics at the design point utilized for this study. 


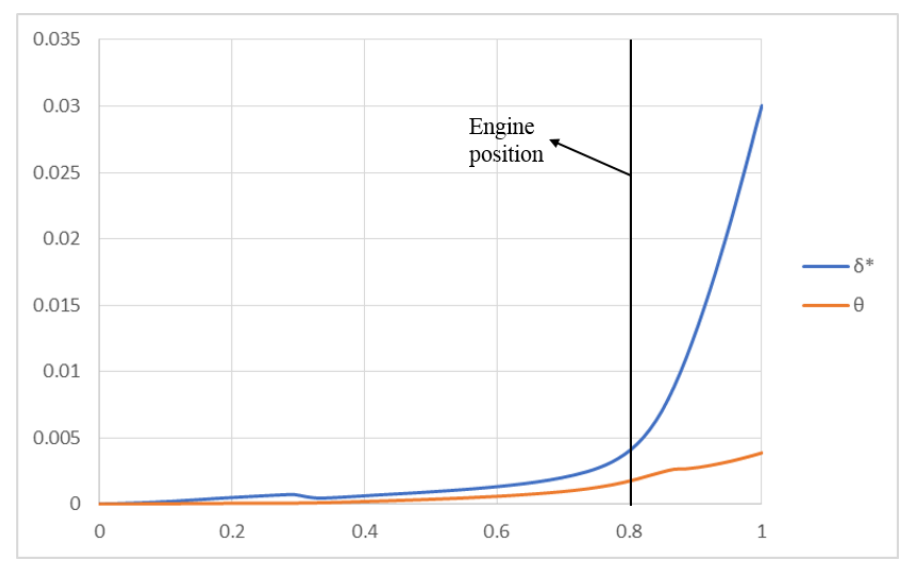

Fig. 14 XFOIL boundary layer data

Table 2 Main engine specifications and fan design characteristics at the design point

\begin{tabular}{c|c}
\hline Parameter & Value \\
\hline Mach number at cruise & 0.85 \\
\hline fan efficiency & $86.9 \%$ (Uniform) $86.2 \%$ (Distorted) \\
\hline Intake pressure losses & $1.5 \%$ \\
\hline Fan pressure ratio & 1.19 (Uniform) 1.25 (Distorted) \\
\hline Fan face Mach number & 0.85 (Uniform) 0.71 (Distorted) \\
\hline Bypass ratio & 5.10 \\
\hline TET (K) & 1535 \\
\hline Overall pressure ratio & 32.7 \\
\hline
\end{tabular}

The TSFC at cruise condition for both the Non-BLI and BLI models are tabulated in Table 3 below. It shows TSFC reduces by $11.2 \%$ at the cruise condition with the application of BLI.

Table 3: Prediction of TSFC for Non-BLI and BLI condition

\begin{tabular}{c|c|c|c}
\hline Parameter & Non-BLI & BLI & Improvement \\
\hline TSFC(kg/daN.h) & 0.627 & 0.557 & $11.2 \%$ \\
\hline
\end{tabular}

\section{Conclusion \& Future Research}

This paper describes a new conceptual level aircraft design, analysis, and optimization environment called GENUS, which is being developed by the Aircraft design group at Cranfield University. The goal is to consider all multidisciplinary aspects of the comprehensive configuration, focusing on key technical points (such as mass breakdown, packaging and control stability), and to increase the level of reliability during the design process, ultimately providing an optimized configuration with an accurate assessment of the potential benefits. In addition to 
analyzing individual class of vehicle, this feature will better enable comparisons between conventional and advanced conceptual configurations.

The methodologies appropriate to the blended wing body are developed based on GENUS, which vary from empirical regressions to physics-based numerical solutions, and different aircraft disciplines containing multiple levels of fidelity.

In addition, boundary layer ingestion has been considered in the aerodynamics analysis process and the benefit of BLI will be explored from the comparison between the performance of the conventional podded engine and embedded engines with BLI.

The Cranfield BW-11 has been chosen as a basic model for validation, and it shows reasonable results in several disciplines. A type of highly fuel- efficient BWB concept can be explored based on this model.

Future work includes developing an acoustic module to predict noise performance for the BWB concept and considering the influence of engine inlet structure on the engine performance in the BLI model. A CFD approach can be implemented as a higher-fidelity way to generate the boundary layer characteristics.

\section{Acknowledgments}

The authors would like to thank Dr. Yicheng Sun and Mr. Eduardo Sepulveda palacios for providing help in the coding work and thank Dr. P. Okonkwo and Dr. D. Sziroczak for their contributions to the GENUS framework.

\section{References}

[1] Okonkwo, P., \& Smith, H. (2016). Review of evolving trends in blended wing body aircraft design. Progress in Aerospace Sciences, 82, 1-23. https://doi.org/10.1016/j.paerosci.2015.12.002

[2] Smith, H., Sziroczák, D., Abbe, G. E., \& Okonkwo, P. (2018). The GENUS aircraft conceptual design environment. Proceedings of the Institution of Mechanical Engineers, Part G: Journal of Aerospace Engineering, 0(0), 1-16. https://doi.org/10.1177/0954410018788922

[3] Sziroczak, D. "Conceptual design methodologies appropriate to hypersonic space and global transportation systems," Aircraft Design Group. Vol. Ph.D., Cranfield University, UK, 2015.

[4] Sun, Y., \& Smith, H. (2018). Supersonic Business Jet Conceptual Design in a Multidisciplinary Design Analysis Optimization Environment. 2018 AIAA/ASCE/AHS/ASC Structures, Structural Dynamics, and Materials Conference, (January). https://doi.org/10.2514/6.2018-1651

[5] Sepulveda, E., Smith, H., \& Sziroczak, D. (2018). Multidisciplinary analysis of subsonic stealth unmanned combat aerial vehicles. CEAS Aeronautical Journal, 0(0), 0. https://doi.org/10.1007/s13272-018-0325-0

[6] Sun, Y. and H. Smith. Turbofan Airliner Conceptual Design in Multidisciplinary Design Analysis Optimization Environment. 1st International Conference in Aerospace for Young Scientists. Beijing, P.R.China. 12-13 November 2016

[7] Okonkwo, P.P.C. Conceptual design methodology for blended wing body aircraft. Aircraft Design Group. Vol. Ph.D, Cranfield University, UK, 2016

[8] Howe, D., Aircraft conceptual design synthesis: Professional Engineering Pub., 2000.

[9] Raymer, D.P., Aircraft design: a conceptual approach 4th edition. American Institute of Aeronautics and Astronautics, 2006.

[10] NASA Glenn Research Center. EngineSim Version 1.8a. EngineSim (2015). https ://www.grc.nasa.gov/WWW/k-12/airpl ane/ngnsi m.html. Accessed 23 June 2017

[11] Drela, M. (2009). Power Balance in Aerodynamic Flows, 47(7). https://doi.org/10.2514/1.42409

[12] Hall, D. K. (2016). Boundary Layer Ingestion Propulsion - Benefit, Challenges, and Opportunities. 5th UTIAS International Workshop on Aviatin and Climate Change, (May).

[13] Valencia, E., Nalianda, D., \& Panagiotis, L. (2016). Discretized Miller approach to assess effects on boundary layer ingestion induced distortion, (December). https://doi.org/10.1016/j.cja.2016.12.005

[14] Kimmel, W. M., \& Bradley, K. R. (2004). A Sizing Methodology for the Conceptual Design of Blended-WingBody Transports. SciencesNew York, (September). Retrieved from http://hdl.handle.net/2060/20040110949

[15] Howe, D. (2001). Blended wing body airframe mass prediction. Proceedings of the Institution of Mechanical Engineers, Part G: Journal of Aerospace Engineering, 215(6), 319-331. https://doi.org/10.1243/0954410011533329

[16] Carmichael, R., PAN AIR: Public Domain Aeronautical Software (PDAS) (2015). http://www.pdas.com/panai r.html. Accessed 24 Apr 2017 
[17] Budziszewski, N., \& Friedrichs, J. (2018). Modelling of a boundary layer ingesting propulsor. Energies, 11(4). https://doi.org/10.3390/en11040708

[18] Gur, O., Mason, W. H., and Schetz, J. A. "Full-configuration drag estimation," Journal of Aircraft Vol. 47, No. 4, 2010, pp. 1356-1367.

[19] Osborn W, Moore R, Steinke R. Aerodynamic performance of a 1.35-pressure ratio axial-flow fan stage NASA technical paper report no.: 1299. Washington D.C: NASA; 1978.

[20] Sepulveda Palacios, E., \& Smith, H. (2019). Impact of mission requirements on the design of low observable UCAV configurations. Aircraft Engineering and Aerospace Technology. https://doi.org/10.1108/AEAT-09-20180249

[21] H. V De Castro. The longitudinal static stability of tailless aircraft. Cranfield University College of Aeronautic CU/COA-2000/0018/1, 2000. 


\section{Blended wing body with boundary layer ingestion conceptual design in a multidisciplinary design analysis optimization environment}

Gao, Ziang

AIAA

Gao Z, Smith H. (2020) Blended wing body with boundary layer ingestion conceptual design in a multidisciplinary design analysis optimization environment. In: 2020 AIAA SciTech Forum, Orlando, Florida, 6-10 January 2020, paper number AIAA 2020-1955

https://doi.org/10.2514/6.2020-1955

Downloaded from Cranfield Library Services E-Repository 